\title{
Factors Affecting International Business of Service Sector Based Indian Public Sector Undertakings: A Preferential Analysis
}

\author{
Ankur Panwar ${ }^{1} \&$ Amarjeet Kaur Malhotra ${ }^{2}$ \\ ${ }^{1}$ Chief Engineer, WAPCOS Ltd, New Delhi, A Central Govt. of India PSU, India \\ ${ }^{2}$ Professor \& Dean, School of Management Studies, Ansal University, Gurgaon, India \\ Correspondence: Ankur Panwar, Chief Engineer, WAPCOS Ltd, New Delhi, A Central Govt. of India PSU, India. \\ E-mail: ankurpanwar@yahoo.com
}

Received: September 13, 2017

Accepted: October 5, 2017

Online Published: October 15, 2017

doi:10.5539/ijef.v9n11p137

URL: https://doi.org/10.5539/ijef.v9n11p137

\begin{abstract}
Public Sector Undertakings (PSUs) in India are the entities which have the status of being Government-owned companies. Internationalization of activities is unavoidable these days in order to sustain. There are number of decisions involved when a PSU decides to enter International market. Tackling factors affecting international business are the most crucial decisions which a PSU has to make. Studies have been carried out in the field of International business and PSUs however, there is an absolute dearth of studies regarding awareness about factors affecting international business of service sector based Indian PSUs. This paper analyzes various factors affecting International business for service sector based Indian PSUs. This paper encompasses the boundary of entire International market and effort has been made to cover all continent and prominent regions/ countries. Responses to our questionnaire are collected from employees of service sector based Indian PSUs, employees of International organizations and related experts in the field of international business. This research study is exploratory in nature. The judgemental or purposive sampling method is used in the study. The data collected from various sources is interpreted and analysed with the help of need based statistical techniques. The descriptive analysis of the responses obtained from them has been done in the study. In descriptive analysis the measure of central tendency (mean, median), dispersion (standard deviation), minimum and maximum scores are estimated. Preferential mapping has also been used in the study to know the preferences of the respondents. In this research paper various factors affecting international business for service sector based Indian PSUs, in various international regions e.g. Africa, Middle East, Western Europe, Central \& Eastern Europe, Asia, Australia, North America, Latin America \& the Caribbean and preferred entry modes, promotional \& operational strategies for most important factors have been found out through secondary data information and primary data analysis.
\end{abstract}

Keywords: PSU, service sector, international business, business affecting factors, international markets, entry methods, promotional strategies, operational strategies, preferential mapping, descriptive analysis

\section{Introduction}

Public Sector Undertakings (PSUs) in India are the entities which have the status of being Government-owned companies. Internationalization of activities is unavoidable these days in order to sustain. There are number of decisions involved when a PSU decides to enter International market. Tackling factors affecting international business are the most crucial decisions which a PSU has to make. Studies have been carried out in the field of International business and PSUs however, there is an absolute dearth of studies regarding awareness about factors affecting international business of service sector based Indian PSUs.

This research paper has four dimensions; first is International Business, second is Indian PSU, third is service sector based firm and fourth is factors affecting International business.

The term "international business" refers to all those business activities which involve cross-border transactions of goods, services, and resources between two or more nations (Wikipedia, 2017).

The service sector, also called tertiary sector, is third of the three traditional economic sectors. The other two are the primary sector, which covers areas such as farming, mining and fishing; and the secondary sector which covers manufacturing and making things (Wikipedia, 2016). 
Service-sector productivity largely determines a nation's ability to compete in today's global economy. An analysis of the comparative productivity levels of several leading countries provides insights into the factors that make a difference. (Mckinsey quarterly, 1992).

Public Sector Undertakings (PSUs) in India are the entities which have the status of being Government-owned companies. In accordance with the Companies Act, 2013, the PSUs mean any company in which not less than fifty one per cent of the paid-up share capital is held by the Central Government, or by any State Government or Governments, or partly by the Central Government and partly by one or more State Governments, and includes a company which is a subsidiary company of such a Government company. Based upon sizes of PSUs, they can be of Maharatna, Navratna, Miniratna category I and II types (Department of Public Enterprise, 2016).

Factors affecting International business are Demographic proximity, Psychic proximity, Political stability, Economic growth, Socio cultural environment, Natural resources, Technological environment and Legal environment (Joshi, 2005).

In this research paper various factors affecting international business for service sector based Indian PSUs, in various international regions e.g. Africa, Middle East, Western Europe, Central \& Eastern Europe, Asia, Australia, North America, Latin America \& the Caribbean and preferred entry modes, promotional \& operational strategies for most important factors have been found out through secondary data information and primary data analysis.

\section{Literature Review}

As per Blomstermo, Sharma, and Sallis (2005), There is a growing interest in researching the internationalization process of service firms (Aharoni, 1993; Aharoni \& Nachum, 2000; Andersson, 2002; Bouquet et al., 2004; Li, 1995; Nachum, 1999; Ochel, 2002; Roberts, 1999).

Increasing competition in the global markets has driven more challenges and opportunities to both private and public sector companies world-wide. However, few businesses have recognized the full scope of performance improvements that globalization makes possible and developing sustainable strategies for capturing these opportunities appears to be still a far cry for public sector companies of developing countries. The public sector undertaking (PSU) companies need to grow from their base and explore global markets in the manufacturing, marketing, services, and consultation sectors. Opportunities in global markets are abundant; however, some firms look on to them with myopic vision while others develop a strategic vision to gain long term sustainable growth as well as competitive advantage. In this manner the firms compete under strategic interdependence. Companies from developing countries have entered the market expansion game too late and have failed in business operations due to various organizational, economic, and cross-cultural issues. The business related issues for PSU companies are to move global complying with the five stages of globalization spread over market entry, product specialization, economies of scale, value chain reengineering, and the creation of new markets. Different levels of global market management are used for cutting costs and creating value that companies can use in each phase. (Institute of Public Enterprise, 2013).

Despite the importance of the service sector in world markets and the growth of foreign investments in this area during the past decade, the research on services in an international context is still limited compared with research that focuses on the manufacturing sector. (Peinado, Barber, \& Hébert, 2007).

Business is affected by different factors which collectively form the business environment. These include economic, social, legal, technological and political factors. Business environment is therefore, the total of all external forces, which affect the organization and the business operations (Kotler \& Armstrong, 2004).

Analyzing similarities and dissimilarities prevalent in countries given wisdom; selecting a country for business enkindles spirit and minimizing risks knocks the door of success. (Frediz 79).

From the point of view of entry mode selection, a firm should evaluate the Political and Economic risks. Political instability and turmoil dissuades firms from committing more resources to a market. Economic risk may arise due to volatility of exchange rates of the target market's currency, upheavals in balance of payments situations that may affect the cost of other inputs for production, and marketing activities in foreign markets. International companies find it difficult to manage their operations in markets wherein the inflation rate is extremely high. (Chand, 2016).

A business designs its competitive strategy to deliver advantages in the marketplace, but the market situation may evolve. Knowing which factors affect the strategy lets you monitor key variables and adjust your actions to take advantage of changes and opportunities. As markets shift under the influence of the actions of your competitors, you have to modify your strategy to continue delivering the competitive advantages you need to 
remain profitable. (Markgraf).

Social and cultural factors are important to consider while creating and implementing a marketing strategy of a company. These often-linked but somewhat different factors have diverse effects on the decisions of consumers and buyers. Basically, sociocultural factors are customs, lifestyles and values that characterize a society. More specifically, cultural aspects include aesthetics, education, language, law and politics, religion, social organizations, technology and material culture, values and attitudes. Social factors include reference groups, family, role and status in the society. (Kozenkow)

It is important for managers to understand the business environment because it can affect their firm and how it should be run. No business is insulated from the outside environment. Things like political decisions, for example, can have a huge impact on a firm by changing tax laws or regulatory regimes. (Phonpei, 2012, p. 397).

For a multinational company to succeed in their overall business mission they need to venture in the host's country's market very wisely. Getting into the right entry mode is an important decision for the company and it demands a lot of planning. My own views about what should be done in future in order that international business becomes more open to the global countries and its markets is that to take a wide range of internal and external factors into consideration before making the final decision. (Marked by teacher).

There have been studies carried out in the field of International Business, PSUs and service sector separately in the past however it is difficult to find a study combining working of service sector based Indian PSU and International Business. There is absolute dearth of any previous studies carried out in the field of finding and devising policies for factors affecting International business pertaining to service sector based Indian PSUs. A study is therefore required to analyze the most important factors and strategies to handle them for Indian service sector based PSUs in various International regions. Therefore this paper could be a primitive and original effort in this direction which will help in understanding the entire dynamics.

\section{Objectives}

To analyze the respective importance of factors affecting International business for Indian service sector based PSUs, preferred factors in various International regions, preferred entry methods and strategies in International markets based on these factors.

\section{Research Methodology}

This research study is exploratory in nature. In this study besides Primary data and its analysis, lot of secondary data from journals, books, websites and experience based data/ information has been utilized extensively.

\subsection{Sampling Frame}

This paper encompasses the boundary of entire International market and effort has been made to cover all continent and prominent regions/ countries. Responses to our questionnaire are collected from employees of service sector based Indian PSUs, employees of International organizations and related experts in the field of international business.

Population: The population of the study includes all PSUs operating in India.

Target Population: The target population includes the PSUs which are in service sector only.

Unit of study: The unit of study is of two types

- Indian PSUs in service sector (for secondary data )

- Executives associated with Indian Service sector PSUs and International business (for primary data study)

Sample Size: The sample size in the study is 120 . The primary data is collected from the 120 executives who are directly or indirectly associated with the service sector based PSUs in India. The primary data is also cross-sectional in nature

Sampling Technique: The judgemental or purposive sampling method has been used in the study.

\subsection{Type of Data and Data Collection}

In the study primary as well as secondary data has been collected. The primary data has been collected with the help of self-designed questionnaire. The questionnaire is prepared with the help of academic guide as well as industry professionals working in service sector Indian PSUs. In addition to this, the secondary sources e.g. the websites, reports and published information have also been used for gathering information. The Primary and secondary data have been collected during May'2016- Dec' 2016. 


\subsection{Variables Considered in the Study}

The following variables have been considered in the study with respect to service sector based Indian PSUs

- Factors affecting international business

\subsection{Data Analysis and Methods}

Data has been analysed by deriving the references from various sources and deriving the conclusion out of it or by means of observing the response. The data collected from various sources is interpreted and analysed with the help of need based statistical techniques. Emphasis is given on the discovery of new ideas and insights into the proposed research topic.

The collected information has been suitably classified and tabulated with the help of statistical tools like trends, correlation, regression, etc. Details of statistical methods used are given as follows.

\subsubsection{Frequency Distribution}

\section{Descriptive analysis}

In the research study the primary data is collected from the executives associated with the service sector based Indian PSUs and experts involved in international business. The descriptive analysis of the responses obtained from them is done in the study. In descriptive analysis, the measure of central tendency (mean, median), dispersion (standard deviation), minimum and maximum scores are estimated.

\section{Preferential mapping}

The preferential mapping is a statistical method used to study the preferences of the respondents towards different available options on the basis of provided attributes. The preferential mapping can be done with the help of discriminant analysis. In the study the preferential mapping is used in following cases:

- To study the preferences of the respondents about the different regions in the world with respect to different factors affecting international business of the service sector based Indian PSUs

- To study the preferences of the respondents about the different methods of entering into international business with respect to different factors affecting international business of the service sector based Indian PSUs

- To study the preferences of the respondents about the different Promotional strategies adopted by service sector Indian PSUs for the purpose of entering into international business with respect to different factors affecting international business of the service sector based Indian PSUs.

- To study the preferences of the respondents about the different Operational strategies adopted by service sector Indian PSUs in international business with respect to different factors affecting international business of the service sector based Indian PSUs.

\subsubsection{Software Used}

In the research study, MS Excel and SPSS 21 have been used for the purpose of data analysis.

\subsubsection{Presentation of the Study}

The study is based on the Primary and secondary data. The data collected from various sources has been analyzed critically.

\section{Analysis}

Primary data collected from the executives/ professional associated directly or indirectly with the international business of the Indian PSUs has been analyzed for this paper. The responses from these professional are collected with the help of self-designed questionnaire. The frequency distribution, descriptive statistics is estimated in the study. The discriminant analysis is also done in the study in order to study the perceptual mapping of the respondents.

From secondary data, 8 possible factors have been found, which can influence the decision of going international. These are listed below

- Demographic proximity

- Psychic proximity

- Political stability

- Economic growth 
- Socio cultural environment

- Natural resources

- Technological environment

- Legal environment

These possible factors are mentioned in the questionnaire $\&$ the respondents are required to rate these factors against different parts of the world, selected for international business by service sector based PSUs. The rating is provided by the respondents in the scale of 1-10 where 1 means least important and 10 means extremely important. The preferential analysis is applied on the collected data and the results are discussed below.

The Table 1 represents the statistical fitness of the preferential analysis done using discriminant analysis.

Table 1. Eigenvalues and canonical correlation

\begin{tabular}{ccccc}
\hline E responses & Eigenvalue & \% of Variance & Cumulative & Canonical Correlation \\
\hline 1 & .131 & 76.8 & 76.8 & .340 \\
2 & .019 & 10.9 & 87.7 & .135 \\
3 & .010 & 6.0 & 93.8 & .101 \\
4 & .007 & 4.3 & 98.0 & .085 \\
5 & .002 & 1.2 & 99.3 & .046 \\
6 & .001 & .7 & 100.0 & .035 \\
7 & .000 & .0 & 100.0 & .004 \\
\hline
\end{tabular}

As shown in the results, it is found that the Eigen value of first function is found to be 0.131 which explains $76.8 \%$ of the variance of the responses. The second function has the Eigen value of 0.019 and explains $10.9 \%$ of the variance. In total, the two functions explain $88 \%$ of the variance of the responses, hence the two factors can be used to analyze the preferential analysis using the discriminant analysis method. These two factors are represented by X-axis and Y-axis respectively. The Canonical correlation of these two factors is found to be 0.340 and 0.135 respectively which indicates the correlation between expected and observed values of dependent variable i.e. countries in this case.

The Table 2 represents the results of poorness of fit of the analysis represented by Wilks' Lambda

Table 2. Wilks' Lambda

\begin{tabular}{ccccc}
\hline Test of Function(s) & Wilks' Lambda & Chi-square & Df & Sig. \\
\hline 1 through 7 & .850 & 142.530 & 56 & .000 \\
2 through 7 & .962 & 34.482 & 42 & .788 \\
3 through 7 & .979 & 18.311 & 30 & .953 \\
4 through 7 & .989 & 9.316 & 20 & .979 \\
5 through 7 & .997 & 2.954 & 12 & .996 \\
6 through 7 & .999 & 1.102 & 6 & .981 \\
7 & 1.000 & .012 & 2 & .994 \\
\hline
\end{tabular}

The results indicate that the Wilks' Lambda of function $1 \& 2$ is found to be 0.85 and 0.962 . This represents the presence of enough variations in the responses.

As the two functions are represented by $\mathrm{X}$-axis and Y-axis respectively, the coordinates of these two axis are provided in Table 3 for all the factors considered in the study. For demonstration purpose, only first two factors are used in the study.

The results of Standardized canonical discriminant function coefficients are shown below in Table 3 . 
Table 3. Standardized canonical discriminant function coefficients

\begin{tabular}{|c|c|c|c|c|c|c|c|}
\hline & \multicolumn{7}{|c|}{ Function } \\
\hline & 1 & 2 & 3 & 4 & 5 & 6 & 7 \\
\hline Demographic proximity & .199 & -.058 & .589 & .050 & -.968 & .611 & .411 \\
\hline Psychic proximity & .827 & .004 & -.329 & .297 & .736 & -.326 & -.517 \\
\hline Political stability & .351 & .817 & .208 & -.224 & -.287 & .138 & -.411 \\
\hline Economic growth & -.055 & -.285 & .005 & .204 & -.194 & -.632 & .332 \\
\hline Socio cultural environment & .041 & .086 & .820 & -.097 & .307 & -.462 & .312 \\
\hline Natural resources & -.169 & .095 & .177 & .547 & .487 & .490 & .256 \\
\hline Technological environment & .400 & -.521 & -.268 & -.589 & .252 & .583 & .219 \\
\hline Legal environment & .182 & .490 & -.626 & .181 & -.178 & -.080 & .521 \\
\hline
\end{tabular}

The results indicate that all the 8 factors on the basis of X\&Y coordinates can be divided into 4 quadrants. The factors Psychic proximity, political stability, socio cultural environment and legal environment fall in first quadrant as both $\mathrm{X}$ and $\mathrm{Y}$ coordinates are positive. The factor natural resources lies in the second quadrant as $\mathrm{X}$ coordinate is found to be negative and $\mathrm{Y}$ coordinate is positive. Demographic proximity and Technological environment fall in quadrant 3 followed by Economic growth which lies in the quadrant 4 . The preferential analysis also calculates the coordinates of different countries considered in the study. The results of the $\mathrm{X}$ and $\mathrm{Y}$ coordinates of all the countries are represented in Table 4.

Table 4. Functions at group centroids

\begin{tabular}{lccccccc}
\hline \multirow{2}{*}{ Country } & \multicolumn{7}{c}{ Function } \\
\cline { 2 - 8 } & 1 & 2 & 3 & 4 & 5 & 6 & 7 \\
\hline Africa & .332 & -.135 & .155 & .061 & -.024 & .002 & .006 \\
Middle East & -.265 & -.120 & .007 & -.113 & .095 & .013 & .002 \\
Western Europe & .446 & .094 & .109 & -.129 & -.021 & -.001 & -.005 \\
Central and Eastern Europe & -.241 & .156 & -.062 & -.058 & -.026 & -.063 & .004 \\
Asia & .494 & -.112 & -.218 & -.005 & -.018 & .015 & .000 \\
Australia & -.424 & -.201 & .016 & .057 & -.028 & -.036 & -.005 \\
North America & .151 & .147 & .001 & .131 & .057 & -.007 & -.002 \\
Latin America \& the Caribbean & -.413 & .093 & -.004 & .010 & -.039 & .060 & .000 \\
\hline
\end{tabular}

Unstandardized canonical discriminant functions evaluated at group means

The results indicate that the countries Western Europe and North America fall in the first quadrant followed by Central \& Eastern Europe and Latin America in quadrant 2, Middle East and Australia in quadrant 3. Finally Africa and Asia fall in quadrant 4. Hence on the basis of Table 3 and 4, it can be concluded that the North America and Western Europe are preferred due to Psychic proximity, socio cultural environment, Legal environment and political stability. Latin America and Eastern Europe are preferred for natural resources and Middle East \& Australia are preferred for Economic growth. Asia and Africa are preferred for demographic proximity and Technological environment.

Table 5. Region wise preference of International business affecting factors

\begin{tabular}{ll}
\hline Region & Preference For the factors \\
\hline North America, Western Europe, & Psychic proximity, Sociocultural Environment, Legal Environment and Political stability \\
Latin America and Central and eastern Europe & Natural resources \\
Middle East and Australia & Economic Growth \\
Asia and Africa & Demographic proximity and technological environment \\
\hline
\end{tabular}

\section{Frequency Distribution: Factors affecting international business}

When an Indian PSU tries to identify the scope of International Business, the decision may be affected by various types of factors in the study. Eight factors were identified to be included in the questionnaire for study. The executives associated with the PSUs in India were asked to provide their responses against these selected factors in the scale of 1-5 where 1 means strongly disagree and 5 means strongly agree. The frequency distribution of the obtained responses are analyzed in the study. The analysis done on the basis of estimated 
frequency distribution is explained below.

Table 6. Frequency distribution

\begin{tabular}{lccccc}
\hline Factors & Strongly disagree & Disagree & Neither disagree nor agree & Agree & Strongly agree \\
\hline Demographic Proximity & 2 & 3 & 18 & 84 & 13 \\
& $(1.7 \%)$ & $(2.5 \%)$ & $(15 \%)$ & $(70 \%)$ & $(10.8 \%)$ \\
Psychic proximity & 2 & 2 & 33 & 45 & 38 \\
& $(1.7 \%)$ & $(1.7 \%)$ & $(27.5 \%)$ & $(37.5 \%)$ & $(31.7 \%)$ \\
Political Stability & 2 & 2 & 12 & 65 & 39 \\
& $(1.7 \%)$ & $(1.7 \%)$ & $(10 \%)$ & $(54.2)$ & $(32.5)$ \\
Economic growth & 3 & 1 & 24 & 38 & 54 \\
& $(2.5 \%)$ & $(0.8 \%)$ & $(20 \%)$ & $31.7 \%)$ & $(45 \%)$ \\
Socio cultural environment & 0 & 1 & $(25 \%)$ & $(40.8 \%)$ & $(33.3 \%)$ \\
Natural resources & $(0 \%)$ & $(0.8 \%)$ & 19 & 54 & 40 \\
Technological & 1 & 6 & $(15.8 \%)$ & $(45 \%)$ & $(33.3 \%)$ \\
environment & $(0.8 \%)$ & $(5 \%)$ & 19 & 72 & 28 \\
Legal environment & 0 & 1 & $(15.8 \%)$ & $(60 \%)$ & $(23.3 \%)$ \\
& $(0 \%)$ & $(0.8 \%)$ & $(15 \%)$ & 62 & 37 \\
\hline
\end{tabular}

The results of frequency distribution indicate that in case of Demographic proximity, more than $80 \%$ of the respondents are found to agree. Only $3 \%$ of the respondents are found to disagree, that demographic proximity may not be the factor which affects International business. In the study it is observed that demographic proximity is one of the important factor which influences the decision of going international. This is due to the reason that demographic proximity leads to less transportation cost, better communication and delivery. In fact demographic proximity leads to comfort in almost all aspects of carrying out business in a foreign country. Countries with demographic proximity tend to be natural target markets due to lower physical distances and logistic complexities. Neighboring countries tend to be natural target markets especially for services with lower values. For example despite a number of political and economic barriers, a wide range of Indian PSUs provide services in Bangladesh, Nepal, Bhutan, Sri Lanka etc.

In case of Psychic proximity approximately 69\% of the respondents agree that Psychic proximity is also an important factor in case of International business. It helps in better communication and terms of business. In this case $27 \%$ of the respondents were found undecided and 3\% were found to disagree with the statement that the psychic proximity helps in International business. Psychic gaps often create communication barriers reflected in differences of languages, life styles, cultural orientation, awareness levels, political ideologies, or the level of technical skills. As a result, the uncertainty about foreign markets and perceived difficulty in obtaining information about foreign markets is lower and a firm finds it more convenient in dealing with firms in countries with fewer such barriers. The large Indian ethnic population in Middle East, Singapore, UK, USA and Canada constitutes sizable markets for Indian services.

In case of Political stability as a factor influencing the decision of International business, $86 \%$ of the respondents were found agree, $10 \%$ were undecided and 3\% were found to disagree. Most of the respondents believe that Political stability is a very important factor for international business. Political instabilities and turmoil dissuades firms from committing more resources to a market. Companies have greater inclination to invest resources in countries with stable governments and transparent legal systems. Broadly political system in developed countries e.g. US, UK, Japan and Australia is highly stable and that's the reason there is no hesitation in firms over operating in those countries whereas the political system in many developing countries e.g. Brazil, Pakistan, Argentina and Fiji etc. is turbulent and therefore all companies hesitate in entering these countries for business, as in case of emergency firms are not sure how much of an investment in a country they can take back to their countries. In Politically stable regimes, rules and regulations are clear, there is no uncertainty in business environment, Political focus is clear and therefore transparency is there.

In case of Economic growth $86 \%$ of the respondents agree that economic growth is one of the important factor for international business as it provides better market opportunity for the company. The economic growth in a country opens many opportunities for international companies to fulfill the needs of the customers and can invest 
in new business lines. However $20 \%$ of the respondents were found undecided and $3 \%$ disagree. Economic growth of a country is a key factor of influence for foreign firms to decide about doing business in a particular country. As economic risk may arise due to volatility of exchange rates of the target market's currency, upheavals in balance of payments situations that may affect the cost of other inputs for services and marketing activities in a foreign market. International firms find it difficult to manage their operations in markets where the inflation rate is very high. Thus a firm would be willing to invest more resources in countries with higher levels of economic stability and growth.

In case of socio cultural environment, $84 \%$ of the respondents agreed that this is also an important factor in area of international business of PSUs. Resembling socio cultural environment leads to less efforts in matching the requirements of a foreign country. A very different socio cultural environment in a foreign country will lead to formidable adaptation costs. $25 \%$ were undecided and $1 \%$ were found disagree.

In case of natural resources which is assumed to be one of the important factor for International business, it is observed that around $78 \%$ of the respondents agreed with the statement however $15 \%$ were undecided and $6 \%$ disagreed. The presence of natural resources in a country attracts other multinational companies to take benefit of that. For example if a country has skilled manpower then to provide certain project management services in that country, a firm can hire local resources and thereby can reduce the cost of operation and providing services. Otherwise also in case of availability of natural resources, cost of providing services in a particular country reduces and an Indian PSU can take benefit of being more competitive then as they will not have to arrange those resources from any other country then. Reverse is also true as in a country like Afghanistan where there is no natural resource available, Indian PSUs have to arrange all resources from other countries which makes business tough in Afghanistan.

Technological environment in correct scenario is one of the key factors to influence the international business. Technological environment not only provides the competitive advantage to the company but also helps in offering best quality services at reasonable price. In case of technological environment, $83 \%$ of the respondents were found to agree that it is an important factor for international business. If a country has high technology savvy environment, e.g. good internet and other services exist there, reliable power supply is there, it becomes that much easier to provide quality services in that country, however for this factor $15 \%$ respondents were undecided and only $1 \%$ were found disagree.

In case of legal environment $82 \%$ of the respondents agreed that it affects the decision of international business however $15 \%$ of the respondents were undecided and 3\% were found disagree. As in case of political stability of a country, legal environment of a country is similarly responsible to generate interest in establishment of business in a country. A good legal environment in a country leads to deployment of more resources by a PSU in other country as they have a notion that everything will be fair in case of an arbitration and conflict.

In addition to frequency distribution, the descriptive analysis of the responses is also estimated. The descriptive statistics includes the estimation of Mean score, Standard deviation, Skewness \& Kurtosis. The purpose of descriptive analysis is to analyze the collected responses of the executives with respect to the average opinion, the variance in the responses and the distribution of the responses. The descriptive analysis of the responses is shown below in Table 7.

Table 7. Descriptive statistics

\begin{tabular}{lcccc}
\hline Factors & Mean & Std. deviation & Skewness & Kurtosis \\
\hline Demographic Proximity & 3.842 & 0.778 & -2.222 & 9.060 \\
Psychic proximity & 4.009 & 0.822 & -.204 & -1.037 \\
Political Stability & $\mathbf{4 . 1 9 4 9}$ & .68261 & -.595 & .542 \\
Economic growth & $\mathbf{4 . 1 3 3 3}$ & 1.037 & -1.699 & 4.321 \\
Socio cultural environment & 4.0500 & .84863 & -.935 & 2.684 \\
Natural resources & 4.0417 & .91114 & -1.168 & 2.401 \\
Technological environment & 4.0756 & .62653 & -.055 & -.423 \\
Legal environment & 4.0583 & .92850 & -2.039 & 7.214 \\
\hline
\end{tabular}

The result of descriptive analysis indicates that all the factors are found to have the mean score $>3.8$ which indicates that all the considered factors are considered to be important factors for international business. The results also indicate that the skewness of all the factors is negative which means most of the respondents responded on the higher side (Agree \& strongly agree) in the 5 point interval scale and the Kurtosis of the 
distribution of the responses is found to be Leptokurtic which indicates the narrowed and focused responses received from the respondents.

The result of the descriptive statistics indicates that the factor Political stability is found to have the highest mean score of 4.19. This means Political stability is found to be the most important factor for the decisions related to international business. It can be summarized that political stability of a country is the most significant factor affecting international business in a country as if it is not there, then even if all other factors are present still an MNC will not feel safe in that country to do business e.g. in case of Pakistan.

This is followed by economic growth which is having the mean score of 4.133 with standard deviation of 1.037. This also indicates that the economic growth is also an important factor which influences the decision related to international business of Indian PSUs which is due to the fact that countries with good economic growth provide lot of opportunities in the area of international business e.g. BRICS countries are considered having good economic growth and most of PSUs want to enter these countries for business opportunities. If a country has good GDP, controlled inflation rate, then this becomes the second most important factor affecting international business after political stability of that country for obvious reasons.

All other factors are also having high mean score. Among all, the demographic proximity and psychic proximity are found to have the lowest mean score of 3.482 and 4.009 respectively. The results indicate that the demographic and psychic proximity are least important factors for international business as compared to others. The graph of mean scores of all the factors is shown below in figure.

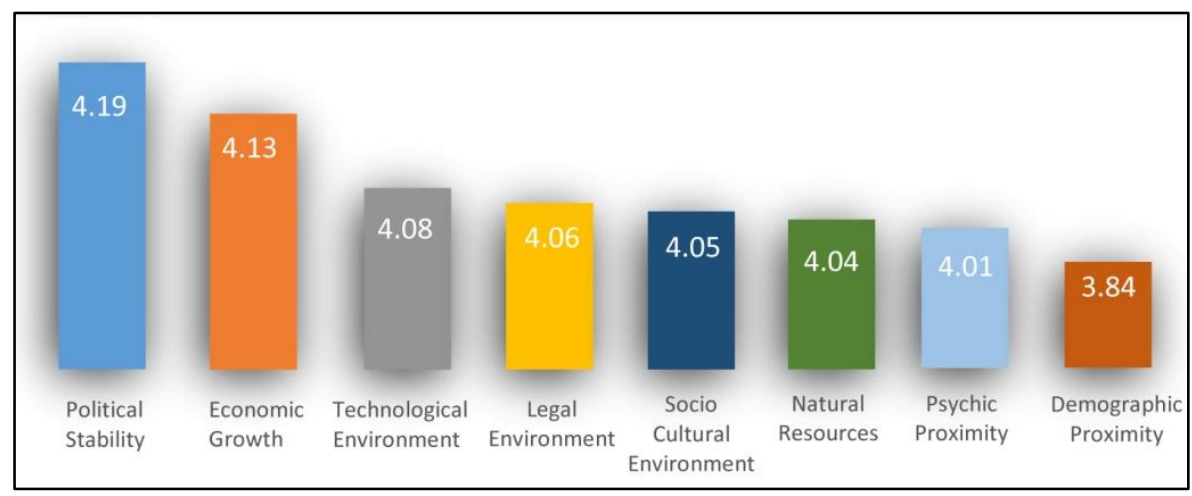

Figure 1. Graph of mean scores of factors affecting international business

In the research paper one objective is to analyze the factors affecting International business vs. Entry modes.

These possible factors are mentioned in the questionnaire $\&$ the respondents are required to rate these factors against entry modes for international business by service sector based PSUs. The rating is provided by the respondents in the scale of 1-10 where 1 means least important and 10 means extremely important. The preferential analysis is applied on the collected data and the results are discussed below.

The Table 8 represents the statistical fitness of the preferential analysis done using discriminant analysis.

Table 8. Eigenvalues \& Canonical correlation

\begin{tabular}{lcccc}
\hline Function & Eigenvalue & \% of Variance & Cumulative \% & Canonical Correlation \\
\hline 1 & $.672^{\mathrm{a}}$ & 57.6 & 57.6 & .634 \\
2 & $.424^{\mathrm{a}}$ & 36.3 & 93.9 & .546 \\
3 & $.052^{\mathrm{a}}$ & 4.4 & 98.4 & .222 \\
4 & $.017^{\mathrm{a}}$ & 1.4 & 99.8 & .128 \\
5 & $.003^{\mathrm{a}}$ & .2 & 100.0 & .051 \\
\hline
\end{tabular}

a. First 5 canonical discriminant functions were used in the analysis.

As shown in the results, it is found that the Eigen value of first function is found to be 0.672 which explains $57.6 \%$ of the variance of the responses. The second function has the Eigen value of 0.424 and explains $36.3 \%$ of the variance. In total the two functions explain $93.9 \%$ of the variance of the responses, hence the two factors can be used to analyze the preferential analysis using the discriminant analysis method. These two factors are 
represented by $\mathrm{X}$-axis and Y-axis respectively. The Canonical correlation of these two factors is found to be 0.634 and 0.546 respectively which indicates the correlation between expected and observed values of dependent variable i.e. Entry modes in International markets in this case.

The Table 9 represents the results of poorness of fit of the analysis represented by Wilks' Lambda.

Table 9. Wilks' Lambda

\begin{tabular}{lcccc}
\hline Test of Function(s) & Wilks' Lambda & Chi-square & df & Sig. \\
\hline 1 through 5 & .392 & 653.181 & 40 & .000 \\
2 through 5 & .655 & 294.748 & 28 & .000 \\
3 through 5 & .933 & 48.559 & 18 & .000 \\
4 through 5 & .981 & 13.313 & 10 & .207 \\
5 & .997 & 1.822 & 4 & .768 \\
\hline
\end{tabular}

The results indicate that the Wilks' Lambda of function $1 \& 2$ is found to be 0.392 and 0.655 . This represents the presence of enough variations in the responses.

As the two functions are represented by $\mathrm{X}$-axis and Y-axis respectively, the coordinates of these two axis are provided in Table 10 for all the factors considered in the study. For demonstration purpose, only first two factors are used in the study.

The results of Standardized canonical discriminant function coefficients are shown below in Table 10.

Table 10. Standardized Canonical discriminant function coefficients

\begin{tabular}{|c|c|c|c|c|c|}
\hline & \multicolumn{5}{|c|}{ Function } \\
\hline & 1 & 2 & 3 & 4 & 5 \\
\hline C3_Demographic_proximity & .452 & -.348 & -.156 & .219 & .495 \\
\hline C3_Psychic_proximity & .637 & -.171 & .086 & .097 & -.426 \\
\hline C3_Political_stability & .123 & .243 & -.311 & -.422 & .828 \\
\hline C3_Economic_growth & .085 & .182 & -.109 & .081 & -.706 \\
\hline C3_Socio_cultural_environment & -.044 & .241 & -.030 & .656 & .080 \\
\hline C3_Natural_resources & .155 & -.003 & .654 & -.628 & -.043 \\
\hline C3_Technological_environment & -.231 & .193 & .681 & .469 & .363 \\
\hline C3_Legal_environment & .342 & .479 & -.140 & -.110 & -.192 \\
\hline
\end{tabular}

The results indicate that all the 8 factors on the basis of $X \& Y$ coordinates can be divided into 4 quadrants. The factors Political stability, Economic growth and legal environment fall in first quadrant as both $\mathrm{X}$ and $\mathrm{Y}$ coordinates are positive. The factors Socio cultural environment and Technological environment lie in the second quadrant as $\mathrm{X}$ coordinate is found to be negative and $\mathrm{Y}$ coordinate is positive. No factor falls in quadrant 3, followed by Demographic, Psychic proximity \& Natural resources which lie in the quadrant 4 . The preferential analysis also calculates the coordinates of different Entry modes considered in the study.

The results of the $\mathrm{X}$ and $\mathrm{Y}$ coordinates of all the countries are represented in Table 11.

Table 11. Functions at group centroids

\begin{tabular}{lccccc}
\hline C3_Entry_modes & \multicolumn{5}{c}{ Function } \\
\cline { 2 - 6 } & 1 & 2 & 3 & 4 & 5 \\
\hline Indirect Export & -.836 & -1.230 & .111 & -.042 & .008 \\
Direct Export & 1.059 & -.460 & -.316 & .119 & -.010 \\
Licensing & -.668 & .520 & -.252 & -.153 & -.051 \\
Franchising & -.727 & .604 & -.042 & .119 & .080 \\
Joint Venture & .070 & .355 & .310 & .129 & -.068 \\
Direct Ownership & 1.097 & .202 & .186 & -.170 & .041 \\
\hline
\end{tabular}

Unstandardized canonical discriminant functions evaluated at group means.

The results indicate that the Entry modes Joint venture and direct ownership fall in the first quadrant followed by Licensing and Franchising in quadrant 2, indirect export in quadrant 3. Finally direct export falls in quadrant 4. 
Hence on the basis of Table 3 and 4, it can be concluded that the Joint venture and direct ownership are preferred due to Political stability, Economic growth and legal environment. Licensing and Franchising are preferred for Socio cultural and Technological environment and indirect export is preferred for none. Direct export is preferred for Demographic proximity, Psychic proximity and Natural resources.

Table 12. Entry mode specific preference of International business affecting factors

\begin{tabular}{ll}
\hline Entry modes & Preference For the factors \\
\hline Joint venture and Direct ownership & Political stability, Economic growth and Legal environment \\
Licensing and Franchising & Socio cultural and Technological environment \\
Indirect export & None \\
Direct export & Demographic proximity, Psychic proximity and Natural resources \\
\hline
\end{tabular}

In the research paper one objective is to analyze the factors affecting International business vs Promotional strategies.

These possible factors are mentioned in the questionnaire $\&$ the respondents are required to rate these factors against Promotional strategies for international business by service sector based PSUs. The rating is provided by the respondents in the scale of 1-10 where 1 means the least important and 10 means extremely important. The preferential analysis is applied on the collected data and the results are discussed below.

The Table 13 represents the statistical fitness of the preferential analysis done using discriminant analysis.

Table 13. Eigenvalues \& Canonical correlation

\begin{tabular}{lcccc}
\hline Function & Eigenvalue & \% of Variance & Cumulative \% & Canonical Correlation \\
\hline 1 & $.419^{\mathrm{a}}$ & 57.5 & 57.5 & .543 \\
2 & $.197^{\mathrm{a}}$ & 27.0 & 84.4 & .405 \\
3 & $.083^{\mathrm{a}}$ & 11.4 & 95.9 & .277 \\
4 & $.025^{\mathrm{a}}$ & 3.4 & 99.3 & .156 \\
5 & $.004^{\mathrm{a}}$ & .6 & 99.9 & .066 \\
6 & $.001^{\mathrm{a}}$ & .1 & 100.0 & .030 \\
\hline
\end{tabular}

a. First 6 canonical discriminant functions were used in the analysis.

As show in the results, it is found that the Eigen value of first function is found to be 0.419 which explains $57.5 \%$ of the variance of the responses. The second function has the Eigen value of 0.197 and explains $27 \%$ of the variance. In total the two functions explain $84.4 \%$ of the variance of the responses, hence the two factors can be used to analyze the preferential analysis using the discriminant analysis method. These two factors are represented by $\mathrm{X}$-axis and $\mathrm{Y}$-axis respectively. The Canonical correlation of these two factors is found to be 0.543 and 0.405 respectively which indicates the correlation between expected and observed values of dependent variable i.e. promotional strategies in International business in this case.

The Table 14 represents the results of poorness of fit of the analysis represented by Wilks' Lambda.

Table 14. Wilks' Lambda

\begin{tabular}{lcccc}
\hline Test of Function(s) & Wilks' Lambda & Chi-square & df & Sig. \\
\hline 1 through 6 & .528 & 512.479 & 48 & .000 \\
2 through 6 & .749 & 231.996 & 35 & .000 \\
3 through 6 & .896 & 88.021 & 24 & .000 \\
4 through 6 & .971 & 23.819 & 15 & .068 \\
5 through 6 & .995 & 4.170 & 8 & .841 \\
6 & .999 & .718 & 3 & .869 \\
\hline
\end{tabular}

The results indicate that the Wilks' Lambda of function $1 \& 2$ are found to be 0.528 and 0.749 . This represents the presence of enough variations in the responses.

As the two functions are represented by $\mathrm{X}$-axis and Y-axis respectively, the coordinates of these two axis are provided in Table 15 for all the factors considered in the study. For demonstration purpose, only first two factors are used in the study. 
The results of Standardized canonical discriminant function coefficients are shown below in Table 15 .

Table 15. Standardized Canonical discriminant function coefficients

\begin{tabular}{lcccccc}
\hline & \multicolumn{7}{c}{ Function } \\
\cline { 2 - 7 } & 1 & 2 & 3 & 4 & 5 & 6 \\
\hline C4_Demographic_proximity & .288 & .195 & 1.214 & .171 & .101 & -.250 \\
C4_Psychic_proximity & .495 & .114 & -.351 & .276 & -.333 & .102 \\
C4_Political_stability & .170 & .676 & -.646 & -.116 & .509 & -.504 \\
C4_Economic_growth & .073 & .359 & .153 & -.616 & -.511 & .536 \\
C4_Socio_cultural_environment & -.386 & .204 & -.141 & .902 & -.074 & .139 \\
C4_Natural_resources & -.340 & -.324 & -.080 & -.187 & .086 & .828 \\
C4_Technological_environment & .099 & -.037 & .167 & -.019 & .953 & .332 \\
C4_Legal_environment & .518 & -.797 & -.107 & .155 & -.085 & .081 \\
\hline
\end{tabular}

The results indicate that all the 8 factors on the basis of $X \& Y$ coordinates can be divided into 4 quadrants. The factors Demographic proximity, Psychic proximity, Political stability and Economic growth fall in first quadrant as both $\mathrm{X}$ and $\mathrm{Y}$ coordinates are positive. The factor Socio cultural environment lies in the second quadrant as $\mathrm{X}$ coordinate is found to be negative and $\mathrm{Y}$ coordinate is positive. The factor Natural resources falls in quadrant 3 , followed by Technological and Legal environment which lie in the quadrant 4 . The preferential analysis also calculates the coordinates of different Promotional strategies considered in the study.

The results of the $\mathrm{X}$ and $\mathrm{Y}$ coordinates of all the countries are represented in Table 16.

Table 16. Functions at group centroids

\begin{tabular}{|c|c|c|c|c|c|c|}
\hline \multirow[t]{2}{*}{ C4_Promotional_strategies } & \multicolumn{6}{|c|}{ Function } \\
\hline & 1 & 2 & 3 & 4 & 5 & 6 \\
\hline Better Quality Service & .384 & -.059 & -.180 & .210 & -.108 & .027 \\
\hline Improved Brand Image & -.076 & .491 & -.152 & .212 & .104 & -.010 \\
\hline Sponsor International Events & -.451 & .611 & .038 & -.131 & -.076 & -.037 \\
\hline Audio Visual Ads & -1.015 & -.061 & .027 & -.113 & .023 & .050 \\
\hline Packaging & -.460 & -.834 & .100 & .076 & .005 & -.037 \\
\hline International Visibility & .820 & .066 & .577 & -.035 & .019 & .010 \\
\hline Global Pricing Strategy & .793 & -.211 & -.417 & -.217 & .031 & -.003 \\
\hline
\end{tabular}

Unstandardized canonical discriminant functions evaluated at group means.

The results indicate that the Promotional strategies International visibility falls in the first quadrant followed by Improved brand image and Sponsor International events in quadrant 2, Audio visual ads and Packaging in quadrant 3. Finally Better quality service and Global pricing strategy fall in quadrant 4 . Hence on the basis of Table 15 and 16, it can be concluded that the International visibility is preferred due to Demographic proximity, Psychic proximity, Political stability and Economic growth. Improved brand image and Sponsor International events is preferred for Socio cultural environment and Audio visual ads \& Packaging is preferred for Natural resources. Better quality service and Global pricing strategy are preferred for Technological and Legal environment.

Table 17. Promotional strategy specific preference of international business affecting factors

\begin{tabular}{ll}
\hline Promotional Strategies & Preference For the factors \\
\hline International visibility & Demographic proximity, Psychic proximity, Political stability and \\
& Economic growth \\
Improved brand image and Sponsor International events & Socio cultural environment \\
Audio visual ads and Packaging & Natural resources \\
Better quality service and Global pricing strategy & Technological and Legal environment \\
\hline
\end{tabular}

In the research paper one objective is to analyze the factors affecting International business vs. Operational strategies. 
These possible factors are mentioned in the questionnaire $\&$ the respondents are required to rate these factors against Operational strategies for international business by service sector based PSUs. The rating is provided by the respondents in the scale of 1-10 where 1 means the least important and 10 means extremely important. The preferential analysis is applied on the collected data and the results are discussed below.

The Table 18 represents the statistical fitness of the preferential analysis done using discriminant analysis.

Table 18. Eigenvalues \& Canonical correlation

\begin{tabular}{lcccc}
\hline Function & Eigenvalue & \% of Variance & Cumulative \% & Canonical Correlation \\
\hline 1 & $.308^{\mathrm{a}}$ & 87.9 & 87.9 & .485 \\
2 & $.034^{\mathrm{a}}$ & 9.8 & 97.8 & .182 \\
3 & $.008^{\mathrm{a}}$ & 2.2 & 100.0 & .088 \\
\hline
\end{tabular}

a. First 3 canonical discriminant functions were used in the analysis.

As show in the results, it is found that the Eigen value of first function is found to be 0.308 which explains $87.9 \%$ of the variance of the responses. The second function has the Eigen value of 0.034 and explains $9.8 \%$ of the variance. In total the two functions explain $97.8 \%$ of the variance of the responses, hence the two factors can be used to analyze the preferential analysis using the discriminant analysis method. These two factors are represented by $\mathrm{X}$-axis and Y-axis respectively. The Canonical correlation of these two factors is found to be 0.485 and 0.182 respectively which indicates the correlation between expected and observed values of dependent variable i.e. Operational strategies in International business in this case.

The Table 19 represents the results of poorness of fit of the analysis represented by Wilks' Lambda.

Table 19. Wilks' Lambda

\begin{tabular}{lcccc}
\hline Test of Function(s) & Wilks' Lambda & Chi-square & df & Sig. \\
\hline 1 through 3 & .734 & 139.146 & 24 & .000 \\
2 through 3 & .959 & 18.671 & 14 & .178 \\
3 & .992 & 3.505 & 6 & .743 \\
\hline
\end{tabular}

The results indicate that the Wilks' Lambda of function $1 \& 2$ are found to be 0.734 and 0.959 . This represents the presence of enough variations in the responses.

As the two functions are represented by X-axis and Y-axis respectively, the coordinates of these two axis are provided in Table 20 for all the factors considered in the study. For demonstration purpose, only first two factors are used in the study.

The results of Standardized canonical discriminant function coefficients are shown below in Table 20.

Table 20. Standardized canonical discriminant function coefficients

\begin{tabular}{lccc}
\hline & \multicolumn{3}{c}{ Function } \\
\cline { 2 - 4 } & 1 & 2 & 3 \\
\hline C5_Demographic_proximity & -.225 & -.517 & .092 \\
C5_Psychic_proximity & .815 & .106 & -.287 \\
C5_Political_stability & .290 & .447 & -.162 \\
C5_Economic_growth & .154 & .285 & .722 \\
C5_Socio_cultural_environment & -.487 & .736 & -.047 \\
C5_Natural_resources & -.034 & -.478 & .266 \\
C5_Technological_environment & .102 & -.263 & -.278 \\
C5_Legal_environment & -.091 & -.205 & .581 \\
\hline
\end{tabular}

The results indicate that all the 8 factors on the basis of $X \& Y$ coordinates can be divided into 4 quadrants. The factors Psychic proximity, Political stability and Economic growth fall in first quadrant as both $\mathrm{X}$ and $\mathrm{Y}$ coordinates are positive. The factor Socio cultural environment lies in the second quadrant as $\mathrm{X}$ coordinate is found to be negative and Y coordinate is positive. The factor Demographic proximity, Natural resources and Legal environment fall in quadrant 3 , followed by Technological environment which lies in the quadrant 4 . The 
preferential analysis also calculates the coordinates of different Operational strategies considered in the study.

The results of the $\mathrm{X}$ and $\mathrm{Y}$ coordinates of all the strategies are represented in Table 21.

Table 21. Functions at group centroids

\begin{tabular}{lccc}
\hline C5_Operational_strategies & \multicolumn{3}{c}{ Function } \\
\cline { 2 - 4 } & 1 & 2 & 3 \\
\hline Economies of Scale & -.640 & -.147 & .089 \\
Uniform Practices & -.281 & -.019 & -.146 \\
Decentralized Services & .069 & .307 & .041 \\
Global Organization & .852 & -.142 & .016 \\
\hline
\end{tabular}

Unstandardized canonical discriminant functions evaluated at group means

The results indicate that the Operational strategy; Decentralized services falls in the first quadrant followed by none in quadrant 2, Economies of scale and Uniform practices in quadrant 3. Finally Global organization falls in quadrant 4. Hence on the basis of Table 20 and 21, it can be concluded that the Decentralized services is preferred due to Psychic proximity, Political stability and Economic growth. There is no particular operational strategy which is preferred for Socio cultural environment. Economies of scale and Uniform practices are preferred for Demographic proximity, Natural resources and Legal environment. Global organization is preferred for Technological environment.

Table 22. Operational strategy specific preference of international business affecting factors

\begin{tabular}{ll}
\hline Operational Strategies & Preference For the factors \\
\hline Decentralized services & Psychic proximity, Political stability and Economic growth \\
- & Socio cultural environment \\
Economies of scale and Uniform practices & Demographic proximity, Natural resources and Legal environment \\
Global organization & Technological environment \\
\hline
\end{tabular}

\section{Findings}

The following factors are found to affect international business

- Demographic proximity

- Psychic proximity

- Political stability

- Economic growth

- Socio cultural environment

- Natural resources

- Technological environment

- Legal environment

From analysis it is seen that distant regions i.e. North America, Western Europe have inclination for psychic proximity, Political stability and legal environment whereas Asia and Africa have preference for Technological environment and demographic proximity.

It is observed that all the 8 factors are quite important for affecting international business. However Political stability and economic growth emerge as the most important factors.

From primary data analysis, JV and direct ownership are the preferred entry modes for Political stability and economic growth which are the most important factors affecting international business. As such from secondary data also JV is the preferred mode of entry in foreign market by Indian PSUs. Therefore our results from primary and secondary data analysis match.

International visibility as a promotional strategy is the preferred strategy for most important factors affecting international business i.e. political stability and economic growth. Therefore adopting measures which lead to international visibility is the best promotion strategy. 
As far as operational strategies are concerned, once we are operating in politically stable and high economic growth country, best operational strategy is to have decentralized operation. Which is true also as once we are operating in a safe country then there is no need to have excessive central head quarter control.

Results obtained through analysis of secondary data and primary data match thereby leading to confirmation and culmination of results.

\section{Conclusion}

Internationalization of activities is unavoidable these days. There are number of decisions involved when a PSU decides to enter International market. Tackling factors affecting international business are the most crucial decisions which a PSU has to make, as initial image and future prospects depend on this only. Factors affecting international business can be taken care of, if everything is planned meticulously and a good business model is developed in advance. However there is a major paucity in awareness of policies and culture of a foreign country initially. Therefore based on analysis carried out here, Indian PSU needs to enter International market through nice planning of various important factors to generate confidence.

- Considering all factors analyzed above, it is recommended to use JV in Politically stable and high economic growth country by Indian service sector based PSUs, to enter in International market.

- International visibility as promotional strategy and decentralized operations as operational strategy are the preferred strategies for Indian service sector based PSUs.

- Global publications e.g. ease to do business in a particular country and Country risk index etc. need to be seen before making a decision about entry strategy in International market.

This paper is however mere origin of an idea due to limited data base, which needs to be studied/ explored further. Considering the facts and findings, a design of an extensive research can be developed with a bigger data base to make it even more useful.

\section{References}

Aharoni, Y. (Ed.) (1993). Coalitions and Competition: Globalization of Professional Business Services. Routledge, London.

Aharoni, Y., \& Nachum, L. (Eds) (2000). Globalization of Services: Some Implications for Theory and Practice. Routledge, London.

Andersson, P. (2002). Connected internationalization processes: The case of internationalizing channel intermediaries. International Business $\quad$ Review, $11(3), \quad 365-83$. https://doi.org/10.1016/S0969-5931(01)00065-8

Blomstermo, A, Sharma, D. D., \& Sallis, J. (2005). Retrieved April 10, 2017 from https://www.researchgate.net/publication/215915411_Choice_of_foreign_market_entry_mode_in_service_f irms

Bouquet, C., Hebert, L., \& Delios, A. (2004). Foreign expansion in service industries: Separability and human capital intensity. Journal of Business Research, 57(1), 35-46. https://doi.org/10.1016/S0148-2963(02)00282-5

Chand, S. (2016). $\quad$ Retrieved July $19, \quad 2017$ from http://www.yourarticlelibrary.com/international-marketing/2-factors-affecting-the-selection-of-international -market-entry-mode/5866/

DPE. (2016). Retrieved April 1, 2017 from http://dpe.gov.in/sites/default/files/3rd_PRC_Report_TWO.pdf

Frediz79. (2017). $\quad$ Retrieved July $17, \quad 2017$ from https://www.scribd.com/doc/73947340/3-Key-Factors-Influencing-International Business

Institute of Public Enterprise. (2013). Retrieved April 3, 2017 from http://profrajagopal.com/yahoo_site_admin/assets/docs/IPE_Conference2013.290123118.pdf

Joshi, M. R. (2005). International Marketing. USA: Oxford University Press.

Kotler, \& Armstrong. (2004). Principles of Marketing-Pearson.

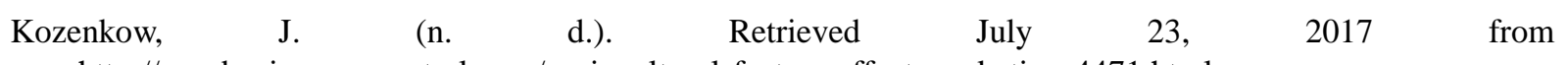
http://yourbusiness.azcentral.com/sociocultural-factors-affect-marketing-4471.html

Marked by teachers. Retrieved July 18, 2017 from http://www.markedbyteachers.com/university-degree/business-and-administrative-studies/factors-affecting-i 
nternational-business.html

Markgraf, $\quad \mathrm{B}, . \quad(\mathrm{n}$.

d.). $\quad$ Retrieved

July

21 ,

2017

from

Mckinsey quarterly.

(1992).

Retrieved

July

27 ,

2017 from http://www.mckinsey.com/global-themes/employment-and-growth/service-sector-productivity-and-internati onal-competitiveness

Nachum, L. (1999). The Origins of the International Competitiveness of Firms: The Impact of Location and Ownership in Professional Service Industries, Elgar, Cheltenham.

Ochel, W. (2002). The international competitiveness of business service firms: The case of Germany. The Service Industries Journal, 22(2), 1-16. https://doi.org/10.1080/714005075

Peinado, E. S., Barber, J. P., \& Hebert, L. (2007). Retrieved April 15, 2017 from https://archive.ama.org/archive/AboutAMA/Pages/AMA\%20Publications/AMA\%20Journals/Journal\%20of \%20International\%20Marketing/TOCs/summary\%20mar\%2007/Strategicjimmar07.aspx

Phonpei397. (2012). $\quad$ Retrieved July $24, \quad 2017$ from https://www.enotes.com/homework-help/why-important-managers-understand-external-341207

Roberts, I. (1999). The internationalization of business service firms: A stage approach.

Wikipedia. (2016). Retrieved April 30, 2017 from https://simple.wikipedia.org/wiki/Service_sector

Wikipedia. (2017). Retrieved July 25, 2017 from https://en.wikipedia.org/wiki/International_business

\section{Copyrights}

Copyright for this article is retained by the author(s), with first publication rights granted to the journal.

This is an open-access article distributed under the terms and conditions of the Creative Commons Attribution license (http://creativecommons.org/licenses/by/4.0/). 